\title{
SENSACIÓN Y PERCEPCIÓN: UNA REVISIÓN CONCEPTUAL
}

Nery Isabel Sánchez-Márquez

Universidad Cooperativa de Colombia

Sede Barrancabermeja

El presente documento de trabajo ha sido incluido dentro de nuestro repositorio institucional como Apropiación social de conocimiento por solicitud del autor, con nes informativos, educativos o académicos. Asimismo, los argumentos, datos y análisis incluidos en el texto son responsabilidad absoluta del autor y no representan la opinión del Fondo Editorial o de la Universidad.

\section{DISCLAIMER}

This coursework paper has been uploaded to our institutional repository as Social Appropriation of Knowledge due to the request of the author. This document should be used for informational, educational or academic purposes only. Arguments, data and analysis included in this document represent authors' opinion not the Press or the University.

Apropiación social del conocimiento

Generación de contenidos impresos http://repository.ucc.edu.co/handle/20.500.12494/7375

N. ${ }^{\circ} 12$, diciembre de 2019 doi: https://doi.org/10.16925/gcnc.11 


\section{ACERCA DE LA AUTORA}

Nery Isabel Sánchez-Márquez, magíster en Educación, especialista en docencia universitaria, psicóloga egresada de la Universidad de La Sabana. Actualmente, es profesora asociada del programa de Psicología, Universidad Cooperativa de Colombia, sede Barrancabermeja, Colombia.

Correo-e: nery.sanchez@campusucc.edu.co / neryisabel@ gmail.com

\section{CóMO CITAR ESTE DOCUMENTO}

Sánchez-Márquez, N. I. (2019). Sensación y percepción: una revisión conceptual (Generación de contenidos impresos N.․ 12). Bogotá: Ediciones Universidad Cooperativa de Colombia. doi: https://doi.org/10.16925/gcnc.11.

Este documento puede ser consultado, descargado o reproducido desde nuestro repositorio institucional (http://repository.ucc. edu.co/handle/20.500.12494/7369) para uso de sus contenidos, bajo la licencia de Creative Commons Reconocimiento-No Comercial-Sin Obra Derivada 4.0 Internacional. http://creativecommons.org/licenses/by-nc-nd/4.0/

\section{(C) (1) $(9)$}




\section{TABLA DE CONTENIDO}

INTRODUCCIÓN

PROPÓSITO DEL CURSO Y COMPETENCIA

Evaluación inicial de presaberes

Solución

UNIDAD I: INTRODUCCIÓN A LA SENSACIÓN Y LA PERCEPCIÓN

PREFACIO

ENFOQUES TEÓRICOS

PSICOFÍSICA

Sensibilidad y umbral

Métodos de medición

Apartado FINAL

ACTIVIDAD DE EVALUACIÓN

Cuestionario

REFERENCIAS

CLASIFICACIÓN

Percepción visual

Percepción auditiva

Sentidos químicos

El gusto

El olfato

Sentidos de la piel

Dolor 


\section{LISTA DE FIGURAS}

Figura 1. Longitud de onda corta y larga 


\section{SENSACIÓNY PERCEPCIÓN:}

Nery Isabel Sánchez-Márquez

\section{RESUMEN}

Esta nota de clase ilustra algunos elementos muy importantes que han sido tenidos en cuenta en la implementación del curso de Procesos Básicos y Complejos, que se desarrolla en el segundo semestre del plan de estudios por competencias en la puesta en práctica de la reforma curricular en el programa de Psicología. Este curso es de carácter formativo, pues comprender el funcionamiento y el impacto de estos procesos en los demás procesos psicológicos es fundamental para la formación del psicólogo. Esta nota de clase constituye una herramienta esencial para el estudiante del curso, toda vez que le permitirá desarrollar las competencias necesarias para reconocer cómo se dan los procesos psicológicos normales de la sensación y la percepción, entre otros, así como identificar la participación de los procesos psicológicos implicados en situaciones de ejecución específicas, los cuales facilitarán el desarrollo de la macrocompetencia consistente en establecer relaciones entre la organización y la dinámica de los procesos psicológicos básicos y complejos, con sus componentes psicobiológicos y psicosociales. Finalmente, cabe resaltar que el estudiante encontrará en esta nota de clase una introducción al tema, lecturas complementarias, cuestionarios y evaluaciones prácticas (tanto al inicio, como al final de cada tema), lo cual propicia el desarrollo de la competencia propuesta.

Palabras clave: percepción, procesos psicológicos, sensación, umbral. 


\section{INTRODUCCIÓN}

Desde el principio de los tiempos, el ser humano se ha preocupado por buscar explicación a los diferentes fenómenos del universo, y al mirar hacia el exterior y encontrar algunas respuestas lógicas a sus muchas preguntas, volcó su mirada hacia el interior para comprender cómo logra asimilar la información, comprender lo que apenas parece comprensible y construir conocimiento.

Primero, la filosofía como madre de todas las ciencias intentó explicarlo; la epistemología centró su interés mucho más en cómo conocemos y al establecer diversas explicaciones (unas radicales, otras más conciliadoras, algunas descabelladas y otras tantas incomprensibles, y con verdades refutables o irrefutables), fueron surgiendo los paradigmas científicos.

Después, otras disciplinas como la física, la anatomía, la biología, la fisiología, la neurología y la química fueron aportando ayudas para confirmar o desconfirmar lo que habían dicho los grandes filósofos. Aún hoy, algunos postulados de las teorías propuestas por Aristóteles sobre la sensación siguen estando vigentes, mientras que otras han permitido profundizar para tener una mayor comprensión de los procesos cognitivos básicos de sensación y percepción.

\section{PROPÓSITO DEL CURSO Y COMPETENCIA}

Esta nota de clase, elaborada específicamente para el estudiante de Psicología del curso de Procesos Psicológicos Básicos y Complejos, está estructurada para que el estudiante evidencie, al finalizar el documento, el desarrollo de la competencia propuesta para el curso, la cual consiste en relacionar aspectos psicológicos que intervienen en el comportamiento individual y social del ser humano.
La competencia por desarrollar facilitará la aprehensión de una base conceptual que permite tomar una decisión al momento de elaborar un diagnóstico, teniendo en cuenta la importancia de la percepción y del procesamiento de información con base en las diferentes modalidades sensoriales. Lo anterior le permitirá al estudiante formular un marco teórico con el fin de explicar el funcionamiento de los procesos psicológicos básicos y avanzados, y comprender su aplicación en diversos contextos. De esta manera, se construye un marco referencial que propicie un proceso de valoración, diagnóstico e intervención basado en la visión integral del ser humano como un ser biopsicosocial.

Cada unidad contiene un corto prefacio en el que se indica su propósito y alcance; después, el desarrollo de los temas y conceptos; y un apartado final con actividades, cuestionarios o ejercicios de revisión y evaluación. Al finalizar, se encuentra un listado de referencias en el que se relacionan los textos, artículos o libros de consulta indispensable y complementaria.

Por lo anterior, cada unidad está planeada para atender un proceso. En la primera unidad, se abordarán las generalidades de los procesos de sensación y percepción; al respecto, lo primero que causa curiosidad en quienes incursionan por primera vez en el campo de la psicología y los procesos cognitivos es la gran profusión de conceptos frente al mismo fenómeno, los cuales varían en designación y profundidad dependiendo de los autores y los hallazgos derivados de sus investigaciones. Por tanto, esta unidad profundizará en la conceptualización desde la psicología como ciencia, pues dicha ambigüedad en los términos, a efectos de clarificar y organizar tanta diversidad, presenta a varios autores alimentando este apartado, tomando especialmente cuatro textos de apoyo por considerarlos de gran utilidad. 
La segunda unidad describe las metodologías perceptuales, expone una revisión del concepto, y en medio de la diversidad de clasificaciones, presenta una aproximación a la comprensión de cada una de ellas y su respectivo componente neuropsicológico.

En este punto, el estudiante terminará discerniendo cada uno de los procesos, su importancia en la conducta de los individuos y su relación con el aprendizaje. Como recomendaciones prácticas sobre esta nota de clase, primero es necesario aclarar que en ningún momento puede ser considerado como información absoluta que reemplace la literatura científica, pues para este caso se pretende aportar al proceso académico del curso tomándola como apoyo didáctico. El programa de curso tiene un listado de referencias semana a semana y actividades que deben ser combinadas con la lectura de la bibliografía; para una mejor comprensión de los conceptos, es de gran utilidad la revisión de los videos anclados y la ejecución de las demostraciones y ejercicios prácticos propuestos. Debe ser claro para el estudiante que el tiempo de dedicación al curso es clave como compromiso personal para facilitar el desarrollo de las competencias propuestas inicialmente.

\section{EVALUACIÓN INICIAL DE PRESABERES}

A continuación, se propone una actividad que pretende identificar los presaberes que usted debe haber desarrollado a nivel cognitivo en el semestre anterior, y que le permitirá tener una mejor comprensión de la nota de clase. Al finalizar la unidad, encontrará la retroalimentación sobre la actividad.

1. Los métodos tienen el objetivo de observar las características morfológicas del sistema nervioso tras disecar el cerebro o alguna de sus partes.

2. Los métodos eléctricos usados en psicofisiología para registrar la actividad eléctrica del organismo son el y el

3. La función principal del es controlar las funciones involuntarias de las vísceras.

4. El está conformado por el encéfalo y la médula espinal.

5. En el lóbulo reside la corteza primaria auditiva.

\section{SOLUCIÓN}

1. Los métodos anatómicos tienen el objetivo de observar las características morfológicas del sistema nervioso tras disecar el cerebro o alguna de sus partes.

2. Los métodos eléctricos usados en psicofisiología para registrar la actividad eléctrica del organismo son el polígrafo y el osciloscopio

3. La función principal del sistema nervioso autónomo es controlar las funciones involuntarias de las vísceras.

4. El sistema nervioso central está conformado por el encéfalo y la médula espinal.

5. En el lóbulo temporal reside la corteza primaria auditiva. 


\section{UNIDAD 1: INTRODUCCIÓN A LA SENSACIÓN Y LA PERCEPCIÓN}

Quítense las sensaciones de suavidad, humedad, color rojo, acidez, y se elimina

la cereza. En virtud de que no es un ser distinto de estas sensaciones; una cereza, digo, no es nada sino un montón de impresiones sensibles o ideas percibidas por varios sentidos; ideas que son unidas en una cosa...

(George Berkeley, 1713, citado en Coren, Ward y Enns, 2001).

\section{PREFACIO}

Apreciado estudiante, en esta unidad se hace necesario efectuar un proceso introductorio frente a la sensación y la percepción como procesos psicológicos básicos. Este apartado requiere de manera indispensable la ubicación teórica de los fundamentos psicobiológicos en los cuales se soportan los procesos y las distintas aproximaciones teóricas desde la psicología, elementos que fueron abordados en el curso de Psicobiología en el semestre anterior. Así, comprender e identificar las estructuras involucradas en el proceso de sensación y luego en el de percepción y su respectivo funcionamiento representan las competencias a desarrollar en el curso.

Estos procesos han sido objeto de estudio desde los filósofos griegos como Aristóteles en su memorable obra De Anima, en la que contempló la importancia de los órganos de los sentidos en sus tres libros, abordando de manera particular cada uno de los cinco sentidos relacionándolo con cómo conocemos y desde un enfoque empirista, dando una explicación epistemológica a cómo desarrollamos el conocimiento y cómo aprendemos gracias a la experiencia. Imposible dejar de lado a Galeno, quien realizó algunas aproximaciones conceptuales sobre los nervios sensoriales y motores, estudios comprobados siglos más tarde por otros científicos. Descartes, en el siglo xVI, con su libro El hombre máquina, inició la investigación del estudio de los reflejos. Por su parte, Wundt enfatizó la importancia de medir de manera objetiva los procesos y, en su afán de buscar cientificidad para la psicología, hizo grandes aportes a la psicología fisiológica como área que permite explicar el funcionamiento y la relación existente entre los estímulos físicos y las reacciones de los organismos a través de la psicofísica.

Son innumerables las investigaciones que se ven en el desarrollo histórico, entre ellas se destacan como importantes las aportaciones de Bell en el siglo Xvir sobre las raíces dorsales en la médula. En el siglo Xviı, se destacaron Gall con sus investigaciones de frenología, Muller con sus estudios sobre la percepción de la visión y el espacio, Purkinje con los estudios histológicos, Weber con su ley de psicofísica para medición de umbrales, Flourens al identificar la importancia del cerebelo en ciertas funciones de coordinación, Luria y sus estudios en el control voluntario e involuntario, y Helmholtz al estudiar la conducción de los impulsos nerviosos, al igual que Galvani en el siglo anterior. En el siglo xx, los estudios de Sherrington se centraron en el sistema nervioso y su papel en el comportamiento; en tanto que Lashley enfatizó en las consecuencias de las lesiones cerebrales.

Como se puede evidenciar, desde sus inicios el estudio científico de los procesos psicológicos, en busca de dar explicación a la conducta del ser humano, se ha caracterizado 
principalmente por un marcado énfasis en hacer claridad sobre lo que se entiende por cada proceso, su localización dentro y fuera del cerebro y la explicación del funcionamiento de cada una de las estructuras implicadas. Esto ha generado diversidad de estudios e investigaciones desde el método científico tanto en animales como en seres humanos, dándole el carácter de disciplina científica a la psicología.

Es indudable lo necesario del estudio de la sensación y la percepción y las razones por las cuales los psicólogos deben estudiar y ser conocedores de estos procesos, principalmente por la comprensión que da de cómo conocemos el mundo interno y externo, y de la relación que tiene con el aprendizaje y el comportamiento del ser humano.

\section{CONCEPTUALIZACIÓN}

Existen diversas definiciones de estos procesos. En este apartado, tomaremos algunos de los más destacados. La percepción se define como "la captura mediante los sentidos que realizan los organismos" (Fernández-Abascal, Martín y Domínguez, 2010, p. 80). Para Matlin y Foley (1996, p. 2), la sensación se refiere a "experiencias inmediatas y básicas, generadas por estímulos aislados simples"; mientras que la percepción incluye la interpretación de esas sensaciones, dándoles significado y organización.

Schiffman (2004, p. 2), por su parte, relaciona la percepción con los procesos iniciales de detección y codificación de la energía ambiental. Conceptúa el autor que la percepción se refiere al producto de procesos psicológicos en los que están implicados el significado, las relaciones, el contexto, el juicio, las experiencias pasadas y la memoria. Otros autores consideran que el proceso engloba un sistema complejo que influye en el procesamiento de la información de los tipos abajo-arriba y arriba-abajo.
Para Munkong y Juang (2008, citado en Vilatuña et al., 2012), el proceso perceptivo es el mecanismo sensorio-cognitivo de gran complejidad mediante el cual el ser humano siente, selecciona, organiza e interpreta los estímulos, con el fin de adaptarlos mejor a sus niveles de comprensión.

En general, es viable determinar que la sensación hace referencia al ingreso y la detección de la información que ha sido registrada y recepcionada por los receptores sensoriales que se encuentran alojados en los órganos sensoriales; y la percepción hace referencia a la organización, integración, reconocimiento e interpretación de esa información. La primera es dada a un nivel de órganos sensoriales, es decir, fuera del cerebro; mientras que la segunda inicia su camino a partir del momento en que cada nervio toma la información de cada modalidad, por tanto, se da a nivel cerebral según el área que corresponda.

\section{ENFOQUES TEÓRICOS}

En este apartado, se describen algunos de los enfoques teóricos que han pretendido explicar la sensación y la percepción. El enfoque empirista, como corriente fuertemente establecida en los siglos XVII y XVII, afirma que "la única fuente de verdadero conocimiento acerca del mundo es la experiencia sensorial, es decir, aquello que se ve, se oye, se gusta, se huele o se siente" (Schiffman, 2004, p. 5).

Thomas Hobbes, John Locke, George Berkeley y William James son los principales representantes del empirismo; enfoque que establece que "las experiencias sensoriales básicas son combinadas por el aprendizaje para producir la percepción" (Matlin y Foley, 1996, p. 6). En ese sentido, Locke (citado por Schiffman, 2004, p. 5) afirma que "la mente estaba inicialmente vacía, era una tabula rasa o pizarra en blanco sobre la cual se escribían las experiencias proporcionadas por los sentidos. Así, los 
contenidos de nuestra mente son la suma de nuestras experiencias sensoriales".

Una forma de explicarla un poco complementaria surge a través del enfoque estructuralista en manos de Wilhelm Wundt y Edward Titchener, quienes se enfocaron en determinar la estructura de la percepción, revelando los elementos más simples de la experiencia consciente a través de las sensaciones elementales. En contraposición a los enfoques anteriores, surge el de la Gestalt estableciendo la capacidad innata del ser humano para percibir, formulando los principios que explican la percepción a través de unas leyes que establecen que se perciben objetos bien organizados como estructuras completas más que como partes aisladas, separadas (Matlin y Foley, 1996). De cualquier forma, es determinante la influencia de la Gestalt en la explicación que brinda la psicología frente a los fenómenos perceptuales.

Para el conductismo, que se concentró en el estudio objetivo del comportamiento, las investigaciones se limitaron a la utilización de métodos para evaluar las reacciones de los organismos a diferentes estímulos físicos.

Por su parte, el enfoque gibsoniano se opone diametralmente al enfoque empirista y afirma que "nuestras percepciones son ricas y elaboradas, debido a que los estímulos en nuestro medio son ricos en información y no a que nuestros procesos de pensamiento o experiencias proporcionan esa riqueza" (Matlin y Foley, 1996, p. 7). Este enfoque también es conocido como percepción directa, pues establece que el estímulo físico por sí mismo contiene todos los elementos necesarios para poder ser percibido; así mismo, le dio poca importancia a los estudios en laboratorio y mayor validez a los realizados en los ambientes naturales y propios en que se desempeña un sujeto en su cotidianidad, pues a medida que un observador se mueve dentro de su ambiente natural, recoge directamente la información que necesita para tener una percepción adaptativa y efectiva (Schiffman, 2004, p. 7). "El sistema perceptual extrae automáticamente esta información de estímulos porque es importante para la sobrevivencia; además, dicha información está a disposición de quien la percibe sin basarse en un proceso o cálculo cognoscitivo de nivel superior" (Coren et al., 2001, p. 10).

El enfoque de procesamiento de información afirma que la información es procesada a través de etapas interconectadas, lo cual implica que cada uno de ellos depende de los otros para un correcto funcionamiento. El enfoque computacional, por su parte, comparte algunos de los postulados del enfoque gibsoniano en lo concerniente a la riqueza de los estímulos; sin embargo, ve a la percepción como una forma de solución de problemas, existiendo otros procesos de orden superior implicados allí.

\section{PSICOFÍSICA}

"Al estudio de la relación entre las propiedades de los estímulos físicos y las reacciones psicológicas le denomina psicofísica" (Matlin y Foley, 1996, p. 17). Fechner, considerado el padre de la psicofísica, marcó el principio del enfoque experimental en la experiencia psicológica, siendo seguido por otros como Ebbinghaus. Esta valiosa herramienta de estudio indaga desde una mirada cuantitativa la relación que existe entre las dimensiones física y psicológica, es decir, los efectos que tienen los estímulos ambientales en la experiencia perceptual para determinar cuál es el efecto en la experiencia sensorial de la variación en intensidad de cada uno de los estímulos en las diferentes modalidades sensoriales.

Para entender cómo se ha estudiado la experiencia psicológica derivada de la energía física traducida en mensajes electroquímicos que afectan al sistema nervioso produciendo 
sensaciones y percepciones, es clave hacer claridad sobre varios conceptos que forman parte del lenguaje técnico y que se contemplan a continuación.

\section{SENSIBILIDAD Y UMBRAL}

Para determinar la relación ente lo físico y lo psicológico, se hace necesario precisar el concepto de lo que se va a medir y luego determinar cómo medirlo. Surgen los conceptos de umbral y sensibilidad, los cuales pueden ser reconocidos de la siguiente forma: el umbral hace referencia a la cantidad de estímulo necesaria para detectar su presencia y la sensibilidad se refiere a la capacidad del organismo para detectarlo. Así mismo, existen diferentes tipos de umbrales.

El umbral absoluto hace referencia a la menor cantidad de un estímulo requerida para reportar su presencia en el promedio de las ocasiones. El umbral diferencial hace referencia a la menor variación o cambio requerido en la intensidad de un estímulo para producir una diferencia que sea detectada en el promedio de las ocasiones en que un sujeto es sometido a varios estímulos.

Es de anotar que la relación entre umbral y sensibilidad es inversamente proporcional, es decir, a mayor sensibilidad, menor umbral; entonces, se requerirá menor cantidad del estímulo para que el sujeto lo detecte. Por el contrario, a menor sensibilidad, mayor umbral; por lo cual si un sujeto es muy sensible, requerirá una baja cantidad o muy poca intensidad del estímulo para detectar su presencia.

\section{MÉTODOS DE MEDICIÓN}

A medida que la psicofísica avanza, los métodos utilizados para la medición de respuestas a estímulos de variada intensidad se han ido perfeccionando desde hace más de cien años, pasando de los más básicos, hasta llegar a algunos ajustes que permiten a los teóricos estudiosos tener resultados con un mayor nivel de confiabilidad, considerando la complejidad de los problemas a los que se enfrenta esta disciplina al intentar cuantificar la respuesta de los organismos frente a estímulos físicos, dado que los efectos llamados experiencia perceptual son de gran subjetividad con gran diferencia de individuo a individuo.

Siendo una meta importante la medición de la percepción humana (Matlin y Foley, 1996), el inicio se da en la medición clásica de la detección, a partir de la medición de los umbrales absolutos. Para medir el umbral absoluto, se han diseñado diferentes métodos que serán descritos a continuación.

El método del ajuste suele poner la responsabilidad directa de graduar la intensidad del estímulo en el sujeto que recibe el estímulo, que de ahora en adelante para efectos técnicos se llamará observador. Es el método más comúnmente usado en la vida diaria por la rápida obtención del umbral, pero dada la tendencia de los observadores a hacer trampa conlleva un bajo nivel de confiabilidad, por lo que a nivel experimental es poco utilizado.

El método de los límites, propuesto por Emil Kraepelin, fija su atención en los estímulos cercanos al umbral absoluto. El experimentador, es decir, quien se encarga de proveer los estímulos variados al observador, se encarga de presentar estímulos de variada intensidad de manera organizada alternando series de ensayo de tipo ascendente y descendente. La técnica indica empezar con un estímulo que sea fácilmente detectable y posteriormente ir presentando estímulos cada vez más débiles hasta que no puedan ser detectados; aplicando así la serie de tipo descendente. El observador debe responder solo sí o no frente a cada uno de los ensayos suministrados; es decir, la serie de ensayos se detiene cuando el observador alcanza un límite cambiando las respuestas de sí a no o de no a sí. 
Cuando el observador cambia su respuesta, se continúa con una serie de tipo ascendente, esto es, un estímulo que no sea fácilmente detectable por encontrarse por debajo de lo que se considera el umbral y continuar presentando estímulos cada vez más intensos hasta que el sujeto pueda reportar su presencia. Puesto que la principal condición es la alternancia de series descendentes y ascendentes, se requiere agotar en lo posible mínimo seis series de cada una de ellas para un total de doce series por experimento.

A pesar de que este método tiene un mayor nivel de confiabilidad que el de ajuste, suele presentar dos tipos de errores: de habituación y de anticipación. En el error de habituación, los observadores tienden a seguir dando la misma respuesta, aunque el estímulo sea de una mayor o menor intensidad al recibido anteriormente, actuando bajo el principio de "es probable que el estímulo sea el mismo que la última vez, entonces seguiré dando la misma respuesta". Así, en series ascendentes siguen diciendo que no y en series descendentes dicen que sí. Por el contrario, en los errores de anticipación, los observadores se anticipan y cambian su respuesta sin evidencia real, actuando bajo el principio de "es probable que el estímulo sea diferente que la última vez, así que cambiaré mi respuesta" (Matlin y Foley, 1996, p. 21).

Como reacción frente a las deficiencias evidenciadas en dichos métodos, aparece el método de los estímulos constantes en el que después de varias evaluaciones aplicando método del ajuste, se seleccionan entre cinco y nueve estímulos de variada intensidad, de tal forma que el más débil esté claramente por debajo del umbral y el más fuerte esté por arriba. El observador es sometido a estos estímulos presentados ya no en series ascendentes y descendentes, sino de manera aleatoria y en número constante de veces para cada intensidad de estímulo. Si bien es cierto que esta técnica tiene un mayor nivel de confiabilidad que las anteriores, siendo por tanto el más utilizado por los psicofísicos, posee la desventaja de requerir mucho tiempo en el experimento, pues se necesitan pruebas previas para hacer una estimación adelantada y prudente del umbral, de modo que el conjunto de estímulos pueda centrarse alrededor de este, siendo necesario después presentar muchos ensayos en cada nivel de intensidad (Coren et al., 2001, p. 17).

Posterior a los métodos clásicos que determinan el umbral, surge la teoría de detección de señales (TDS), que cuestiona la existencia de un umbral único y establece que existen dos procesos implicados en la determinación del umbral: la sensibilidad del observador y la estrategia o criterio del observador para la toma de decisiones (Baird y Noma, 1978; Gescheider, 1985; Green y Swets, 1966, citados en Coren et al., 2001). Se pone de relieve el papel tan importante de los conceptos previos del observador en la percepción, sustentados en el enfoque de procesamiento de información arriba-abajo que suponen niveles de análisis abstracto generales (Schiffman, 2004, p. 156).

Así mismo, los investigadores han utilizado la TDS para separar la sensibilidad del criterio, partiendo del análisis de las respuestas del observador al incluir en los diferentes ensayos señales y ruidos (entendiendo la señal como la presencia del estímulo físico y el ruido como la ausencia de estímulo físico que ha sido reemplazado por ruido de fondo). Entre los factores que inciden en el criterio se han encontrado las expectativas previas, el pago recibido en términos de premios o castigos al dar determinadas respuestas y la certeza respecto a la probabilidad de que la señal ocurrirá en lugar del ruido.

Son múltiples los usos de la TDS. Durante más de tres décadas ha sido aplicada al estudio de la percepción y evaluación del dolor, y entre otros en el papel del efecto placebo al reportar el dolor. Se encontró en la mayoría de los estudios que el dolor no influye en la 
sensibilidad, pero sí en su criterio para reportar el dolor, pues los observadores siguen sintiendo la misma intensidad de dolor, pero juzgan si inhibir o no la respuesta del reporte o no del dolor. Para profundizar en los estudios y sus resultados, consultar a Matlin y Foley (1996, pp. 34-38).

Los estudios migraron hacia la medición de estímulos más intensos, en los que los investigadores se enfocaron en la discriminación para determinar cuál es la menor cantidad de cambio en un estímulo requerida para que el observador pueda reportar que se dio un cambio o que este es diferente para a encontrar la diferencia apenas perceptible. Continúa la utilización de los mismos métodos clásicos, adaptando cada uno de ellos a las exigencias requeridas por el tipo de estudio. Así, por ejemplo, en el método de ajuste el mismo observador se encarga de ajustar el estímulo comparativo, mientras que, en el método de los límites, el experimentador hace incremento o disminución sistemática del estímulo comparativo, y en el método de los estímulos constantes, se presentan los estímulos comparativos en orden aleatorio.

Son importantes en este reto de medición de estímulos más intensos las leyes planteadas por Weber, Fechner y Stevens, quienes aportaron desde la física diferentes fórmulas o ecuaciones para explicar y describir la relación existente entre el estímulo físico y las reacciones psicológicas.

La ley de Weber establece que el tamaño del umbral diferencial se incrementa de manera lineal con el tamaño de la norma, y si tomamos el cambio en la intensidad y lo dividimos entre la intensidad original, obtenemos un número constante, enfocándose así en las diferencias apenas perceptibles y encontrando que para que un cambio sea detectado, se debe tener en cuenta la intensidad inicial del estímulo, pues entre más intenso sea este, mayor debe ser el cambio para que sea notado por el observador.

Por su parte, la ley de Fechner determina que la magnitud de la respuesta psicológica está relacionada con el logaritmo de la intensidad del estímulo físico. Y la ley de Stevens (conocida como la ley de la potencia) sostiene que la magnitud de la reacción psicológica es igual a una constante multiplicada por la intensidad del estímulo que ha sido elevado a cierta potencia.

\section{APARTADO FINAL}

Al finalizar esta unidad de la nota de clase, usted habrá tenido la oportunidad de conocer los conceptos básicos en torno a los procesos de sensación y percepción que comprometen varios conceptos que se han ido depurando a través del tiempo y en la confluencia de varias disciplinas, entre ellas, la física. Los puntos claves en esta unidad son: los conceptos de sensación, percepción, psicofísica, umbral, sensibilidad; la discriminación un poco sobre el desarrollo histórico de la medición en psicofisiología; los principales métodos utilizados por la psicofísica para medir la reacción psicológica de los seres humanos frente a estímulos físicos; $y$, por supuesto, las leyes que se han establecido para brindar una explicación científica.

Se sugiere la lectura de los capítulos 1 y 2 del libro de Matlin y Foley (1996) y del artículo de Fausto Vilatuña Correa et al. (2012), así como la revisión del video "Sensación y percepción - Descubrir la psicología”, disponible en YouTube en el siguiente enlace: https://www.youtube.com/watch?v=eDowTw0Nf-E

\section{Demostraciones:}

1. Un ejercicio práctico es la aplicación de la guía de laboratorio que aparece a continuación: 


\section{GUÍA DE LABORATORIO \# I}

\begin{tabular}{|l|l|l|}
\hline Tema & \multicolumn{2}{|l|}{ Medición en psicofísica } \\
\hline Subtemas & Umbrales y métodos de medición & \multicolumn{2}{|l|}{} \\
\hline Periodo & 1920 & Fecha \\
\hline Profesor & Nery Isabel Sánchez Márquez & \multicolumn{2}{|l}{} \\
\hline
\end{tabular}

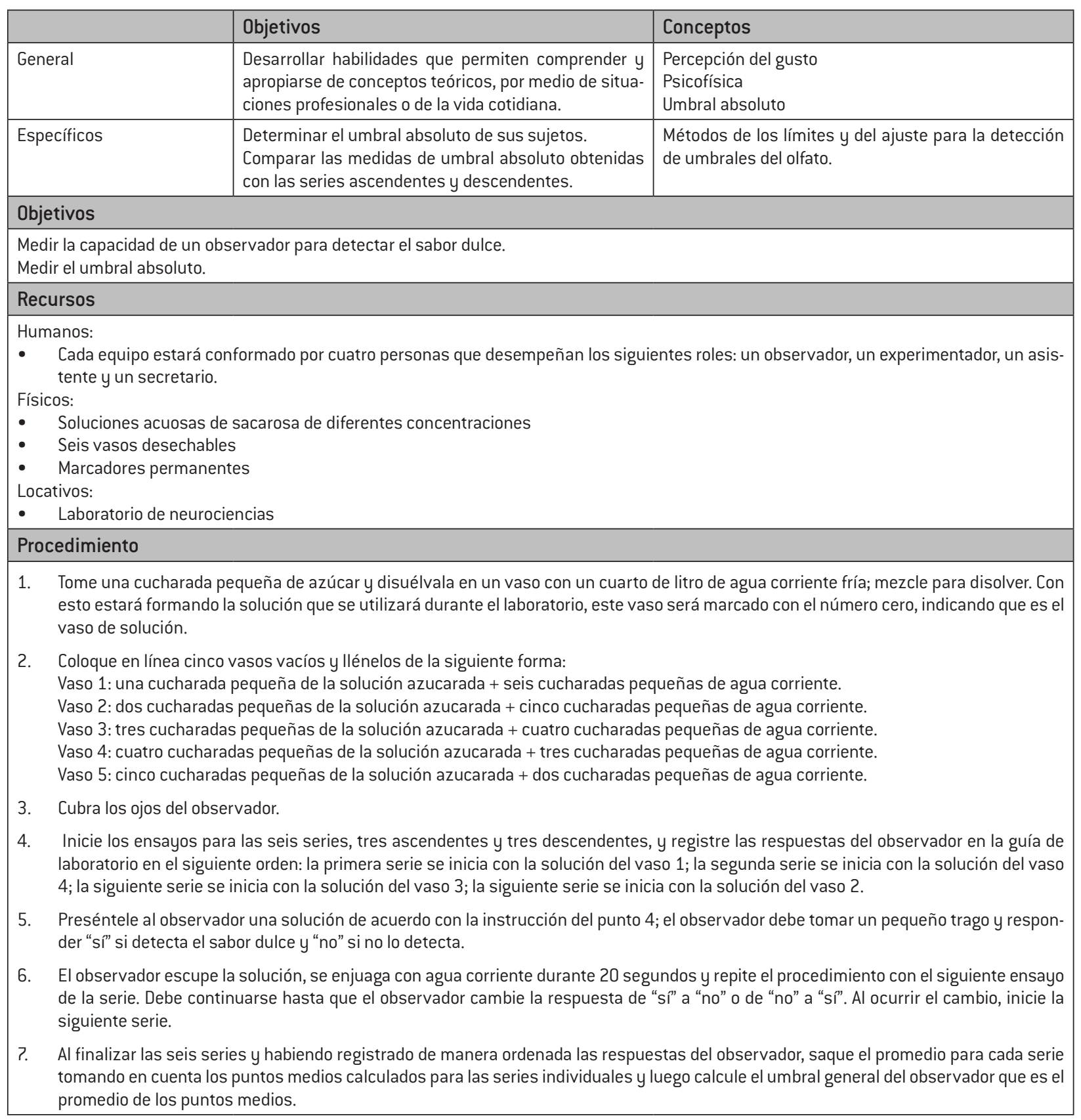




\begin{tabular}{|l|l|l|l|}
\hline \multicolumn{2}{|l|}{ Referencias } \\
\hline Coren, S., Ward, L. y Enns, J. (2001). Sensación y percepción. México D.F.: McGraw-Hill. \\
Hill Pinel, J. (2007). Biopsicología (6. ed.). Bogotá: Pearson Educación. \\
Matlin, M. W. y Foley, H. J. (2006). Sensación y percepción. México D.F.: Prentice Hall. \\
Schifman, H. R. (2004). Sensación y percepción. Un enfoque integrador. México D.F.: Manual Moderno. \\
\hline Total de estudiantes del grupo de trabajo & \multicolumn{3}{l|}{} \\
\hline Nombre del representante del grupo & \multicolumn{2}{|l|}{} & \\
\hline Ciudad & Barrancabermeja & Fecha & \\
\hline & & & \\
\hline Nery Isabel Sánchez Márquez & & & \\
\hline Docente / tutor & Docente / tutor & Líder de laboratorio & Director de programa \\
\hline
\end{tabular}

\section{ACTIVIDAD DE EVALUACIÓN}

La actividad de evaluación propuesta consiste en una serie de preguntas para completar, relacionadas con los conceptos de esta primera unidad. Permitirá evidenciar el desarrollo de las competencias propuestas inicialmente. Al finalizar la actividad, usted encontrará el feedback con el fin de identificar el cumplimiento y repetirla cuantas veces sea necesario, por lo cual se sugiere responder a lápiz para hacer las correcciones pertinentes.

La valoración en este primer ejercicio es una evaluación escrita, pues se requiere evidenciar la claridad en la diferenciación de términos básicos relacionados con la atención, la distinción de cada tipo de atención, los componentes de la atención y el fundamento o sustrato biológico.

\section{CUESTIONARIO}

Complete:

1. Al proceso inicial de detección y codificación de la energía ambiental se le denomina
2. La capacidad de detectar estímulos de variada intensidad se denomina:

3. El proceso de

hace referencia a la organización, integración,

de las $\mathrm{y}$

4. Las leyes establecidas para la medición de estímulos de mayor intensidad son

y

5. Los tres tipos de medición clásicos son $\mathrm{y}$

\section{SOLUCIÓN:}

1. Al proceso inicial de detección y codificación de la energía ambiental se le denomina sensación.

2. La capacidad de detectar estímulos de variada intensidad se denomina: sensibilidad.

3. El proceso de percepción hace referencia a la organización, integración, interpretación y reconocimiento de las sensaciones. 
6. Las leyes establecidas para la medición de estímulos de mayor intensidad son Ley de Weber, Ley de Fechner y Ley de Stevens.
7. Los tres tipos de medición clásicos son método del ajuste, método de los límites y método de los estímulos constantes.

\section{REFERENCIAS}

Ardila, R. (1973). Psicología fisiológica. México D.F.: Trillas.

Bravo, L. (2004). Las destrezas perceptuales y los retos en el aprendizaje de la lectura y la escritura. Una guía para la exploración y comprensión de dificultades específicas. Revista Electrónica Actualidades Investigativas en Educación, 4(1). Recuperado el 14 de noviembre de 2019, de https://www.redalyc.org/ articulo.oa?id=447/44740105

Coren, S., Ward, L., y Enns, J. (2001). Sensación y percepción. México D.F.: McGraw-Hill.

Fernández-Abascal, E., Martín, M. D. y Domínguez, J. (2010). Procesos psicológicos. Madrid: Pirámide.

Matlin, M. W. y Foley, H. J. (1996). Sensación y percepción. México D.F.: Prentice Hall.

Schiffman, H. R. (2004). Sensación y percepción: un enfoque integrador. México D.F.: Manual Moderno.

Téllez-Vargas, J., Taborda, L. C. y Burgos, C. (2000). Psicopatología clínica. El síntoma en las neurociencias. Bogotá: Javegraf.

Vilatuña, F., Guajala Agila, D., Pulamarín, J. y Ortiz Palacios, W (2012). Sensación y percepción en la construcción del conocimiento. Sophia, Colección de Filosofía de la Educación, (13). Recuperado el 16 de octubre de 2019, de https://www.redalyc.org/articulo.oa?id=4418/441846102006 


\section{UNIDAD 2: MODALIDADES PERCEPTUALES}

\author{
"Ilusión que se ve es ilusión que se \\ escucha" \\ (Calderón de la Barca, citado en Téllez, \\ Taborda y Burgos, 2000, p. 235).
}

\section{PREFACIO}

Los seres humanos recibimos información del medio circundante a través de nuestros sentidos, son ellos los que establecen el primer contacto a través de los receptores sensoriales que se encuentran alojados en cada uno de ellos. Este paso inicial se continúa a partir de tres elementos comunes en todas las modalidades, a saber: primero, un estímulo físico que particulariza un tipo de energía específica; segundo, el conjunto de sucesos o hechos mediante los cuales el estímulo se traduce en un mensaje de impulsos nerviosos posterior a la transducción a otro tipo de energía que hace nuestro organismo, posibilitando que nuestro cerebro pueda hacer la interpretación; y tercero, la respuesta que se da al mensaje, la cual da cuenta de un proceso perceptual que se evidencia como respuesta al medio o como representación mental del estímulo y almacenamiento de la información que podrá ser utilizada posteriormente.

Poniendo de relieve la existencia de los órganos de los sentidos, en este apartado se describen cada una de ellas identificando el proceso perceptual particular, la base neuroanatómica y su clasificación. Finalmente, el estudiante encontrará en esta unidad las estructuras que lo conforman y la descripción de su actividad cerebral.

\section{CLASIFICACIÓN}

\section{PERCEPCIÓN VISUAL}

Nuestro sistema visual es el encargado de procesar el estímulo visual a partir de la luz, que no es otra cosa que energía electromagnética. La física explica claramente que su estudio se hace a partir de la descomposición de la luz en ondas luminosas, que son producidas por partículas cargadas electromagnéticamente y se miden en nanómetros ( $\mathrm{nm}$ ), lo cual se traduce en una billonésima parte de un metro.

Tomando como base el espectro luminoso, la ciencia ha establecido que, aunque el ojo humano es un órgano muy completo, perfecto y asombroso, a diferencia de los animales, tiene restricciones para percibir la luz, limitándose solo a una pequeña porción.

Para hacer mayor precisión en su estudio y sus características, ha de entenderse que las ondas luminosas poseen características físicas que se corresponden a su vez con propiedades psicológicas reflejadas en la percepción. Primero, hemos de revisar las características físicas de longitud de onda, amplitud de onda y pureza.

La longitud de onda, como bien lo ha establecido la física, es la distancia que recorre la onda durante un ciclo; en este caso específico, la distancia entre un pico y otro de la onda. Ya que la luz visible al ojo humano es la porción del espectro de ondas que oscilan entre 400 y $700 \mathrm{~nm}$, pueden clasificarse longitudes de onda corta y longitudes de onda larga. 

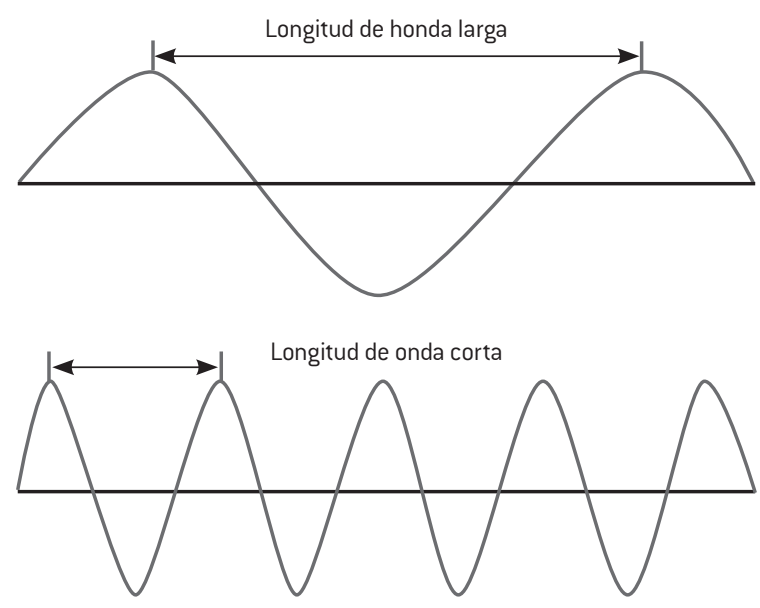

FIGURA 1. Longitud de onda corta y larga. Elaboración propia.

Por su parte, la amplitud de onda es la altura que alcanza una onda luminosa, mientras que la pureza hace referencia a la mezcla de longitudes de onda en la luz.

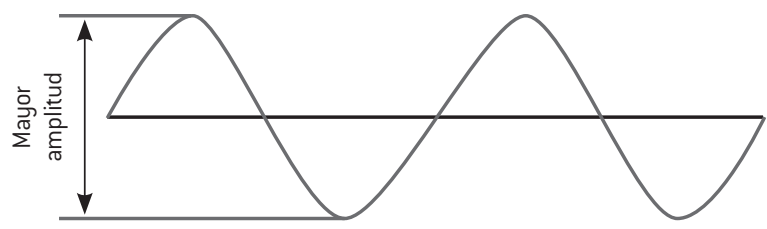

FIGURA 2. Amplitud de onda corta y larga. Elaboración propia.

Ahora bien, si cada una de las características físicas se relaciona con una propiedad psicológica, el equivalente de la longitud de ondas luminosas es el matiz, que es la reacción psicológica del color producida, en parte, por una longitud de onda particular. Así, una longitud de onda corta de $440 \mathrm{~nm}$ se ve representada por el color violeta, mientras una longitud de onda de $470 \mathrm{~nm}$ representa el azul y una longitud de onda larga de $6680 \mathrm{~nm}$ representa el color rojo.

En cuanto a la amplitud o altura de la onda luminosa, su propiedad psicológica es la percepción de brillantez del color, y al variar las ondas en sus crestas, un mismo color puede ser brillante o mate dependiendo de la altura, pues a mayor altura, mayor brillantez y a menor altura, menor brillantez. Por su parte, la pureza como propiedad física se interpreta a nivel psicológico con la saturación percibida de un estímulo visual.

Descrito el estímulo a ser detectado por el aparato visual, se establece su estructura y funcionamiento con el fin de hacer claridad sobre el papel que desempeña cada una de las partes en este proceso, hasta llegar a la transducción o conversión de la energía luminosa en energía nerviosa. Las principales estructuras del ojo de afuera hacia adentro son, en su orden: esclerótica, córnea, pupila, iris, cristalino, retina, fóvea, humor vítreo, humor acuoso, nervio óptico y punto ciego.

La esclerótica es la parte blanca del ojo, su color se debe a que las fibras que la conforman están desorganizadas, lo cual facilita su función de proteger de la luz el interior del ojo. La córnea, aunque está formada del mismo material que la esclerótica, es de color transparente porque las fibras están bien organizadas. Al estar delante del iris y por su forma, cumple la función de desviar los rayos luminosos que entran del exterior para que caigan directamente sobre el globo ocular.

El anillo muscular que da el color al ojo se llama iris, es una membrana parecida a un disco conformado por dos músculos lisos que se encuentran entre la córnea y el cristalino, una de sus funciones es contraer o dilatar para aumentar el tamaño de la siguiente estructura llamada pupila, dispuesta como una abertura en el centro del iris, mediante los mecanismos de contracción (cerrar) y dilatación (abrir), frente a las condiciones diversas de iluminación buena o deficiente (Schiffman, 2004, p. 49).

El cristalino, por su parte, es el lente ubicado detrás de la pupila; a través del proceso de 
acomodación facilita enfocar los objetos a diferentes distancias, adelgazándose ante cortas distancias y engrosándose para distancias mayores, para así mantener en foco sobre la retina. Una estructura de gran importancia por su función de nutrir y oxigenar a la córnea y al cristalino es el humor acuoso, se ubica detrás de la córnea como una pequeña cámara de líquido con estructura similar a la del líquido cefalorraquídeo. El humor vítreo tiene una estructura parecida a la gelatina, ayuda a mantener la forma esférica del globo ocular y a conservar la estructura de la retina.

En la parte posterior del globo ocular, se encuentra ubicada una membrana que contiene los fotorreceptores encargados de absorber la energía luminosa y transducir o transformarla en actividad neuronal; además, contiene diferentes tipos de neuronas sensoriales para transmitir la información al área correspondiente en el cerebro. Existen dos tipos de fotorreceptores: los bastones y los conos. Los primeros son llamados así por su forma cilíndrica, alargada y delgada, y se especializan en detectar la información en blanco y negro y bajo condiciones de baja luminosidad. Los conos son llamados así por su forma cónica, y se especializan en visión en color y bajo condiciones de muy buena luminosidad. En la región central de la retina, se encuentra el punto de mayor agudeza visual especialmente poblado de conos y se denomina fóvea, su tamaño es de unos 0,3 mm de largo; en contraposición, existe el punto ciego creado por el disco óptico, se denomina punto ciego pues no se puede ver nada que caiga en esta parte de la retina dado que carece de fotorreceptores (Matlin y Foley, 1996, p. 58).

El nervio óptico, o haz de terminaciones nerviosas que salen del ojo, se encarga finalmente de enviar la información que se origina en la retina hacia el quiasma óptico, comenzando así el proceso perceptual.

\section{Funciones visuales básicas}

Los procesos visuales básicos requieren de un estímulo físico nítido y una base orgánica en las mejores condiciones como prerrequisitos para una visión normal. Algunos factores importantes son la adaptación a la luz y la oscuridad, la duración de la exposición de la luz, la agudeza visual, el proceso de acomodación realizado por el cristalino, los movimientos oculares, la distancia, el lugar de la pupila por donde ingresa la luz, el área de la retina que ocupa el estímulo distal y las condiciones de fatigabilidad o no del sujeto.

La agudeza visual es una de las condiciones necesarias para la visión, ya que permite ver detalles y discriminar entre estímulos en un espacio determinado. Para Olzak y Thomas (citado en Matlin y Foley, 1996, p. 108), la agudeza mide la capacidad de resolución del sistema visual en términos del detalle más pequeño con contraste más elevado, percibido a una distancia dada.

Existen cuatro tipos de agudeza visual, que son medidos a partir de la determinación del umbral comparado con el resultado obtenido por un observador normal, resultado que ya se encuentra estandarizado después de muchos estudios. Aunque se utilizan diferentes métodos, el más conocido es la tabla de Snellen.

El primer tipo de agudeza es la identificación; el observador deberá identificar una figura, en el caso de la tabla de Snellen se espera que se digan los nombres de las letras colocadas en cada fila. El segundo tipo de agudeza es la detección; requiere que el observador determine si un elemento está presente o no en el espacio demarcado, sea letra, número, línea o cualquier figura. En el tercer tipo de agudeza, denominado resolución, el observador debe juzgar si advierte o no una separación entre las partes de la figura. La agudeza de Vernier es un cuarto tipo de agudeza, y en ella 
el observador deberá determinar la posición relativa entre los objetos que se encuentran presentes.

Los movimientos oculares permiten conservar sobre la fovea los objetos que se encuentran en movimiento. Se clasifican en dos grandes grupos: movimientos de versión y movimientos de vergencia. Los movimientos de versión se presentan cuando el ángulo visual permanece constante, por lo que los ojos se mueven en la misma dirección, pues se sigue un objeto en movimiento, alejado del observador. A su vez, se clasifican en: movimientos sacádicos y movimientos de persecución.

Los movimientos sacádicos se llaman así porque son rápidos y se realizan de un punto fijo al siguiente. Se caracterizan por dos tipos de movimientos combinatorios como son las sacadas, en las que el ojo se mueve de una localización a la próxima (movimiento que frecuentemente hacemos) con una duración de 250 milisegundos, y las fijaciones o pausas entre esas dos movidas o sacudidas, que tienen una duración de 0,2 segundos antes de que el ojo inicie otro ciclo de sacadas y fijaciones. Como se puede inferir, estos son los movimientos utilizados para la lectura.

El otro tipo de movimiento de versión es el de persecución, que se utilizan para seguir objetos que se encuentran en movimiento sobre un fondo fijo y, a diferencia de los sacádicos, es relativamente lento y suave.

El segundo grupo de movimientos oculares se denomina de vergencia; son movimientos lentos, específicos, para que ambos ojos se enfoquen sobre el mismo objetivo cuando cambia el ángulo visual por estar a distancias variables. Así, los movimientos de convergencia hacen que los ojos se acerquen entre sí para observar objetos cercanos y los de divergencia hacen que los ojos se separen para ver objetos lejanos.
La distancia también es un factor importante en las funciones visuales básicas, siendo su percepción necesaria en situaciones cotidianas en las que se debe juzgar, por ejemplo, la distancia relativa entre dos objetos o distancia relativa, la distancia entre usted y el objeto (distancia egocéntrica) y la distancia en términos tridimensionales, es decir, la que le permite percibir la profundidad en los objetos.

Para Foley y Hochberg (citado en Matlin y Foley, 1996, p. 169), existen doce fuentes de información de la distancia que se clasifican en dos grupos: uno grande de factores monoculares y otro pequeño de factores binoculares. Los factores monoculares requieren de un solo ojo para brindarnos información de la distancia, en tanto que los monoculares requieren la confluencia de los dos ojos para obtener información precisa.

Existen diez factores monoculares, de los cuales ocho no requieren movimiento y dos sí lo requieren. Los que no requieren movimiento son, en su orden, los siguientes:

- La acomodación necesaria para enfocar objetos a diferentes distancias y que es ejecutada por el cristalino con ayuda del músculo ciliar.

- La interposición como fuente primaria de información nos lleva a juzgar como más alejado un objeto que está parcialmente cubierto por otro.

- El tamaño del objeto, que puede ser relativo cuando se juzga el tamaño de un objeto respecto a otro u otros, y el familiar cuando se habla del tamaño estandarizado conocido de un objeto.

- El gradiente de textura, que nos proporciona información más precisa sobre las características de la superficie de un objeto a medida que disminuye la distancia o, por 
el contrario, aumentando su densidad a medida que la distancia entre el objeto y el observador aumenta.

- La perspectiva lineal que según Cutting (citado en Matlin y Foley, 1996, p. 173), depende de nuestro punto de vista, pues las líneas paralelas parecen encontrarse en la distancia dando impresión de lejanía.

- La perspectiva atmosférica nos señala que los objetos están distantes porque se ven borrosos y azulados.

- El sombreado transmite información de profundidad en el contraste de luces y sombras.

- Las claves de altura indican que los objetos cercanos al horizonte parecen percibirse más lejos de quien observa.

Los dos factores monoculares que implican movimiento son: el paralaje del movimiento o la perspectiva del movimiento y el efecto de profundidad cinética. El primero indica que el movimiento del observador hace que se genere un cambio continuo en la percepción de los objetos a su alrededor; el segundo indica que un objeto que gira sobre sí mismo, aunque sea plano, genera la impresión de profundidad.

En cuanto a los factores binoculares, se contemplan la convergencia y la disparidad binocular, revisados ya en este mismo apartado. Como se puede observar, se ha dedicado una buena extensión del texto a lo visual por su protagonismo en los procesos de aprendizaje.

\section{PERCEPCIÓN AUDITIVA}

Las investigaciones dan cuenta de que el segundo proceso perceptual más importante es la audición. Aunque Nathan y Evans (citados en Matlin y Foley, 1996, p. 253) sostienen que la importancia evolutiva de la audición es esencial para detectar peligros aun en la actualidad, considerándola más importante que la visión para los humanos.

Al igual que con la visión, abordaremos el estímulo auditivo, sus propiedades, la estructura y funcionamiento del oído y las funciones auditivas básicas.

El estímulo auditivo es energía electroacústica que se desplaza en el aire. Al igual que en la visión, su medición se realiza a partir de lo que para esta modalidad se denomina onda sonora, se mide en Hertz (Hz) y ante los cambios de presión del aire circundante, ingresan al oído y reciben el nombre de sonidos.

Las características físicas del estímulo auditivo son frecuencia y amplitud. La frecuencia es el número de ciclos que una onda sonora completa en un segundo, su correspondiente atributo psicológico es el tono. El oído humano puede percibir entre $20 \mathrm{~Hz}$ y $20.000 \mathrm{~Hz}$, siendo especialmente sensibles a frecuencias entre $2000 \mathrm{~Hz}$ y $5000 \mathrm{~Hz}$ (Guick, Gescheider y Frisina, 1989; Silvian y White, 1933, citados en Matlin y Foley, 1996, p. 255).

La amplitud corresponde al atributo psicológico de la percepción del volumen dada por la máxima presión creada por las ondas sonoras. El volumen depende principalmente de la amplitud, la duración, los ruidos de fondo, las características de quien escucha y la frecuencia.

Otra de las propiedades de la onda sonora es el timbre, que corresponde a la complejidad de la combinación de ondas sonoras, siendo considerado el sello característico de los sonidos. Así por ejemplo en las voces humanas puede percibirse un mismo tono y volumen, pero diferente y único timbre para cada una de ellas.

El oído está dividido en tres partes: oído externo, medio e interno. A continuación, se describe la ubicación y función de manera sucinta para cada una de las partes: 
El oído externo, cuya función es recibir las ondas sonoras y dirigirlas al oído medio, está formado por el pabellón auricular, el canal auditivo externo y la membrana timpánica. El pabellón auricular es la porción externa llamada oreja, su forma ayuda a captary aumentar el sonido. El conducto auditivo externo mide entre $0,8 \mathrm{~cm}$ de diámetro y $2,5 \mathrm{~cm}$ de largo, facilita la amplificación de la frecuencia del sonido y protege el interior del oído al dificultar el ingreso de objetos. La membrana timpánica, mejor conocida como tímpano, es la estructura más importante del oído externo ya que vibra al recibir las ondas sonoras que vienen del exterior pasándolas al oído medio.

El oído medio está conformado por los tres huesecillos (martillo, yunque y estribo) y la trompa de Eustaquio. La función de los tres huesecillos es transferir la información que ha enviado el tímpano, el martillo golpea al yunque y este golpea al estribo inmediatamente, generando comunicación entre ellos. La tuba faringotimpánica, o trompa de Eustaquio, mide unos $4 \mathrm{~cm}$ de promedio en el humano adulto, se compone de una porción ósea y otra cartilaginosa, posee una lámina epitelial compuesta por epitelio nasofaríngeo o epitelio cilíndrico ciliado pseudoestratificado con abundantes células caliciformes, y tiene como función igualar la presión a ambos lados del tímpano pues comunica el oído con la garganta.

El oído interno está conformado por los canales semicirculares y la cóclea. Los canales semicirculares son tres tubos muy pequeños que contienen un líquido cuya función es mantener el equilibrio. Los movimientos de la cabeza hacen que el líquido del interior de los conductos semicirculares se agite moviendo las microvellosidades de cada canal, enviando así al cerebro la información sobre la posición del cuerpo; sin embargo, dado que el tema a tratar es la audición y no el equilibrio, no se profundizará en el tema.

La cóclea o caracol es llamado así por su forma de sistema de tres tubos diferentes enrollados, uno al lado del otro denominados rampa vestibular, rampa media y rampa timpánica. La rampa vestibular y la rampa media están separadas entre sí por la membrana vestibular, la rampa timpánica y la rampa media están separadas por la membrana basilar. En esta estructura coclear, los estímulos sonoros se traducen en ondas viajeras a lo largo de la membrana basilar, y recargado en esta membrana se encuentra el órgano de Corti que contiene células pilosas; la flexión de sus vellosidades convierte la energía sonora mecánica en impulsos neuronales (Coren, Ward y Enns, 2001, pp. 163182). Finalmente, se encuentra el nervio auditivo, que se encarga de enviar la información a la corteza auditiva, haciendo una primera estación en el núcleo coclear, luego al núcleo de la oliva superior, después al colículo inferior y de ahí al núcleo geniculado medial. Por último, está la corteza auditiva, una estructura esencial para la localización del sonido, la percepción del habla y otras tareas auditivas complejas.

\section{Funciones auditivas básicas}

La función auditiva más simple es la detección de los sonidos, esta conlleva en sí misma otras funciones como la identificación, la localización y la discriminación. En nuestra percepción subjetiva del sonido, hay distintas cualidades subjetivas del sonido o propiedades psicológicas como la sonoridad, el volumen, la altura tonal y la consonancia o disonancia de los sonidos.

La sonoridad depende de características como la presión, la adaptación y la fatiga auditiva del oyente. La altura tonal es la reacción psicológica que corresponde a la frecuencia de un tono. 
En cuanto a localización auditiva, incluye la identificación de la dirección y la distancia de un sonido; esta depende de las diferencias de intensidad interaural y la información provista por el pabellón de la oreja y el movimiento de la cabeza. Es claro que la información auditiva y la visual se combinan para crear un mapa del espacio y facilitar el proceso. A nivel neuropsicológico, el núcleo de la oliva superior es importante para la localización del sonido. A diferencia de los seres humanos que tienen ciertas limitaciones, animales como los búhos y murciélagos muestran capacidades de localización auditivas impresionantes.

Respecto a la discriminación o percepción de sonidos presentados simultáneamente, es claro que nunca escuchamos sonidos puros o únicos pues nos encontramos inmersos en un mundo plagado de sonidos diversos que emergen de diferentes fuentes, algunos dirigidos al escucha y otros que aunque no son emitidos para este, generan interferencia. Cuando se combinan dos o más tonos que son percibidos de manera placentera, nos encontramos frente a sonidos consonantes; por el contrario, cuando las combinaciones de varios tonos se juzgan como no placenteras, el sonido es disonante.

En algunas ocasiones, la presencia de un estímulo auditivo impide la percepción adecuada de otro, lo cual se conoce con el nombre de enmascaramiento que puede ser de tipo retroactivo o proactivo. El primero se presenta cuando un segundo estímulo afecta la percepción del primero. A la inversa, en el enmascaramiento proactivo la presencia de un primer estímulo afecta la percepción del que se presente posteriormente.

Otros fenómenos no menos importantes son la adaptación y la fatiga auditiva. La adaptación auditiva ocurre cuando un estímulo auditivo es presentado de manera continua durante un tiempo específico. La literatura científica afirma que en los oídos normales se requiere un minuto para que esto ocurra, así el volumen percibido disminuye frente al real (Evans y Monroe, citado en Matlin y Foley, 1996, p. 310). Por el contrario, la fatiga auditiva ocurre cuando un estímulo sonoro muy fuerte es presentado y luego apagado y reemplazado por un ruido de fondo, lo cual ocasiona un cambio en el umbral para otros estímulos.

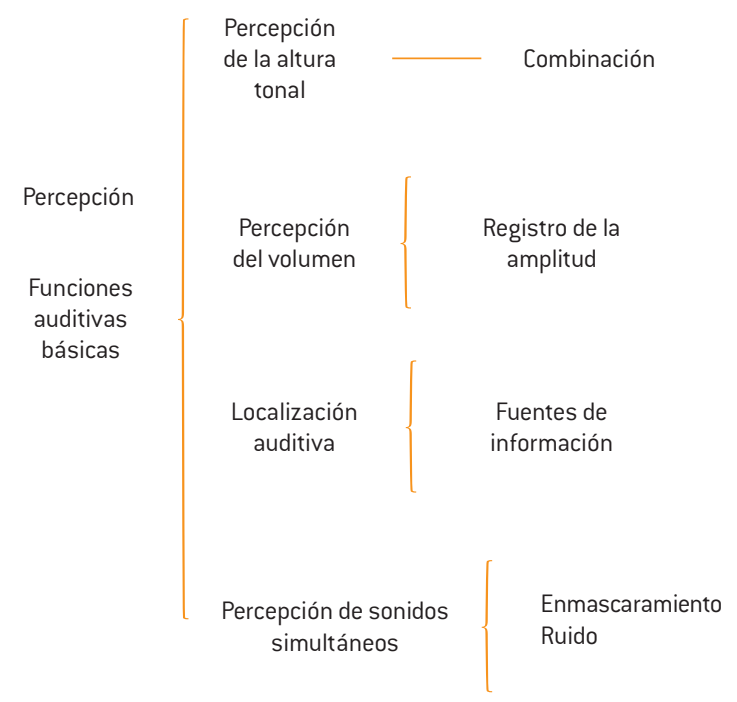

FIGURA 3. Funciones auditivas básicas. Elaboración propia.

\section{SENTIDOS QUÍMICOS}

Los sentidos químicos agrupan al olfato y el gusto, los cuales están muy relacionados al ser sensibles a la estimulación recibida de la energía química que tiene cada sustancia, y aunque no has sido tan estudiados como la visión y la audición, no dejan de ser importantes en relación con el comportamiento del ser humano.

\section{EL GUSTO}

Para nuestro curso estudiaremos inicialmente el gusto, el cual hace referencia a la percepción que resulta del contacto de diferentes sustancias con los receptores que se encuentran localizados en diferentes lugares de la boca; así, el sabor es el producto de una combinación de varias experiencias perceptuales que incluyen también el olfato. 
Los receptores químicos se denominan papilas gustativas o corpúsculos gustativos. Aunque durante mucho tiempo se concibió que solo se alojaban en la lengua, las investigaciones demuestran que no solo están allí, sino también en la garganta, el paladar y la parte interior de las mejillas (Oackley, citado en Matlin y Foley, 1996, p. 433). Así mismo, Collings determinó la relación entre la lengua y el paladar, y encontró que la parte media de la lengua carece de corpúsculos gustativos; podría llamarse punto ciego como en el caso de la visión.

\section{Procesos del gusto}

Al ser la función principal del gusto la detección e identificación de sabores, sigue estando presente - al igual que en las otras modalidades- la importancia de los umbrales y la adaptación.

El umbral de reconocimiento indica la concentración de una solución que puede identificarse mediante alguna propiedad. En esa medida, especifica la cantidad de una sustancia que debe agregarse al agua destilada para que se reconozca el sabor, así los umbrales de reconocimiento son por lo general más elevados. McBurney, Kelling y Halpern (citado en Matlin y Foley, 1996, p. 437) determinaron que no necesitamos un periodo largo de contacto entre el estímulo y los receptores para emitir un juicio.

La adaptación para el gusto, al igual que para las otras modalidades, es la disminución en la sensibilidad cuando un estímulo se presenta continuamente. Por su parte, existen unos efectos de la adaptación a una sustancia sobre la percepción del sabor que se pueda tener sobre otra sustancia; en este caso, se habla de los fenómenos de adaptación y potenciación cruzada.
La adaptación cruzada se presenta cuando la adaptación a una sustancia eleva el umbral hacia otra. Como consecuencia, el sujeto será menos sensible a la segunda sustancia, siendo específica para una propiedad del sabor en particular. Un claro ejemplo se presenta cuando si está adaptado a un sabor agrio, el observador será menos sensible a otros sabores agrios.

La potenciación cruzada es todo lo contrario y ocurre cuando la adaptación a una sustancia disminuye el umbral de otra. Y ya que potenciación es aumento en la sensibilidad, seremos más sensibles a la segunda sustancia (Kuznicki y McCutheon, citado en Matlin y Foley, 1996, p. 437). Un ejemplo que ilustra el fenómeno es que si ha comido un dulce, el jugo que consuma le sabe simple y si es ácido, probablemente lo sentirá más acido de lo normal.

En la percepción del sabor, se destaca la presencia de diversas sustancias especiales que cambian el sabor de los alimentos al modificar los receptores sobre la lengua y se describen a continuación:

- Sabor del agua: fenómeno por el cual el agua puede tener un sabor diferente cuando su lengua se ha adaptado a otro sabor. Así, las sustancias agrias y amargas producen un sabor dulce en el agua y las saladas o dulces, un sabor agrio o amargo.

- Glutamato monosódico: parece combinar los cuatro sabores, pero cuando se agrega a otros alimentos, los umbrales para los sabores agrio y amargo disminuyen.

- Gymnema silvestre: planta de la India y África, disminuye la sensibilidad al dulce y los cristales de azúcar se perciben como arena en la lengua. 
- Fruta milagrosa: cambia el sabor de sustancias agrias, tiene el potencial de transformar el jugo de limón puro que ingerimos en una limonada endulzada. Esta fruta imparte un sabor dulce a las sustancias que se comen a la hora siguiente.

Para finalizar la descripción del gusto, surge el tema de las hedónicas de los alimentos, las cuales implican juicios de gusto y disgusto que son cruciales en nuestra respuesta perceptual a los alimentos al responder a la pregunta: ¿esto sabe bien? La mayoría de los estudios encontraron que las preferencias hedónicas son aprendidas, así las aversiones a diversos alimentos (cebolla, ajo, etc.) se dan por modelamiento o experiencias desagradables.

En cuanto a la relación del gusto con otras modalidades sensoriales, se reportan los estudios de Hyman, Mentzer y Calderone (1979, citado en Matlin y Foley, 1996), quienes encontraron que el olfato es frecuentemente pero no siempre útil para la percepción de sabores, aunque existe una gran interacción con el gusto. Por su parte, la percepción visual parece tener un efecto, pues el color de los alimentos puede influir en las preferencias hedónicas. Johnson y Clydesdale (1982, citado en Matlin y Foley, 1996) afirmaron que las soluciones de azúcar pintadas de rojo eras juzgadas como más dulces que las soluciones sin color; y bebidas con sabor a cereza suelen confundirse con las de sabor a naranja cuando están pintadas de anaranjado (Dubose, Cardello y Maller, 1980, citado en Matlin y Foley, 1996)

La relación con la temperatura de los alimentos es resaltada por McBurney (1978, citado en Matlin y Foley, 1996), quien establece que la mayoría de los estudios muestran que la gente es más sensible a los sabores cuando la sustancia se sirve a temperatura ambiente o a temperatura corporal, con una sensibilidad máxima en un punto entre 22 y $32^{\circ} \mathrm{C}$. La temperatura también influye en el placer según Zellner, Stewart, Rozin y Brown (1988, citado en Matlin y Foley, 1996), quienes a su vez encontraron que la gente prefiere que el té, la leche y el chocolate estén calientes o fríos, pero no a temperatura ambiente; para el agua, el vino y los refrescos de cola la temperatura fría fue preferida a la temperatura ambiente, que a su vez era mejor que la caliente; en tanto que el café y las sopas deben estar calientes preferiblemente.

Al recibir bebidas de sabores poco usuales, como por ejemplo guanábana, tamarindo, borojó, chontaduro y otros propios de ciertas regiones pero no muy generalizados, los observadores reportan que se prefieren frías en lugar de a temperatura ambiente. Sin embargo, como la gente no tiene formadas opiniones a ese respecto, si se le informa que generalmente estas bebidas se sirven a temperatura ambiente, disfruta tanto de ellas si son servidas a temperatura ambiente, como lo hicieron cuando fueron servidas frías.

\section{EL OLFATO}

Es el sentido encargado de detectar y procesar los olores. Actúan como estimulante las partículas aromáticas u odoríferas desprendidas de los cuerpos volátiles, que ingresan por el epitelio olfativo ubicado en la nariz para procesar o convertir las señales químicas en percepción.

Los propósitos básicos son, entre otros: crear una representación del olor, determinar su concentración, distinguir un nuevo olor entre los olores ambientales en segundo plano, identificar los olores en diferentes concentraciones y relacionar el olor con el recuerdo de lo que representa. 
Las estructuras fuera del cerebro son el epitelio olfativo (en la cavidad nasal), el órgano de Jacobson y el nervio olfativo. A nivel cerebral, aparecen el bulbo olfativo, el córtex piriforme, la amígdala y el córtex entorinal.

El proceso inicia con la mucosa olfativa, que consta de tres tipos característicos de células: las células olfativas sensoriales, las células de sostén y las células basales, que se dividen aproximadamente una vez al mes y reemplazan a las células olfativas moribundas. El moco nasal acuoso transporta las moléculas aromáticas a los cilios con ayuda de proteínas fijadoras; los cilios transforman las señales químicas de los distintos aromas en respuestas eléctricas.

Los quimiorreceptores del olfato a su vez son: 1) la glándula pituitaria roja que se ubica en la parte inferior de la fosa nasal y está recubierto por numerosos vasos sanguíneos que calientan el aire inspirado; 2) la glándula pituitaria amarilla, que se ubica en la parte superior de las fosas nasales y presenta tres capas: las células de sostén, las células olfatorias y las células basales.

Entre los procesos inherentes a la percepción olfativa, aparece el umbral diferencial, referido a la diferencia entre dos estímulos que una persona apenas puede identificar. Aunque los umbrales diferenciales no son indispensables para la supervivencia, tienen aplicación al cocinar y comer, así como en otras tareas de la vida civilizada. Un ejemplo se da a través de un estudio que examinó el ácido acético, que huele a vinagre. Las dos muestras de ácido acético deben variar en aproximadamente 26\% para ser detectadas, así la persona deberá ser capaz de notar la diferencia en la intensidad entre 100 y 126 g de vinagre.

En cuanto a la adaptación, al igual que en las otras modalidades, la exposición continua a una sustancia odorante aumenta el umbral, siendo una experiencia común frente a los olores propios del cuerpo o de los odorantes aplicados sobre la piel. Aquí también opera la adaptación cruzada cuando la adaptación a un odorante puede afectar el umbral de otro estímulo odorífero estrechamente relacionado.

El enmascaramiento también está presente en el olfato, suele aparecer cuando la concentración de un olor sobrepasa en forma suficiente la de otro, pero también puede ocurrir que los odorantes tiendan a fundirse generando un tercer olor (Schiffman, 2004, p. 459).

\section{SENTIDOS DE LA PIEL}

Los sentidos de la piel constituyen el sistema sensorial más amplio, con alrededor de $2 \mathrm{~m}$ de superficie receptiva. Sus principales funciones se centran en protegernos de temperaturas extremadamente elevadas o bajas y del daño tisular potencial cuando se siente dolor; contemplan la percepción de tacto, dolor, temperatura y los sentidos cenestésico y vestibular, que le indican al organismo si se está erguido o inclinado, en dónde se encuentran las partes del cuerpo y en qué relación entre sí.

La percepción del tacto comprende a su vez algunas modalidades como la presión, el tacto, la vibración y el cosquilleo. La sensibilidad térmica comprende frío, calor y percepción del dolor (o nocicepción).

Existe un sistema sensorial distribuido por todos los órganos que clasifica la sensibilidad en somática y visceral. La sensibilidad somática se divide a su vez en una sensibilidad superficial, (por originarse en la piel) llamada somestesia y se diferencia de una sensibilidad profunda que afecta a músculos, tendones y articulaciones, y que contribuye al sentido de la cinestesia. 


\section{Aspectos sensoriales del tacto}

El sentido del tacto surge de la estimulación de diferentes tipos de receptores, de los cuales los más estudiados son las terminaciones nerviosas encapsuladas, llamadas corpúsculos de Pacini, que son los órganos terminales sensoriales más grandes en el cuerpo y son muy sensibles a las depresiones de la piel. La información del tacto es transmitida a través de cuatro canales diferentes. El primero de los corpúsculos de Pacini proporciona información a un canal. Los otros tres canales restantes reciben su información de un tipo de fibra de adaptación rápida que responde a cambios en la estimulación, pero cesan de responder cuando hay presión continua sobre la piel; o de dos tipos de fibra de adaptación lenta que responden a una presión continua sobre la piel. Los cuatro canales se distinguen no solo por los receptores involucrados y la velocidad de adaptación, sino también por sus campos receptores (Matlin y Foley, 1996, p. 384).

La adaptación se refiere al proceso por medio del cual el receptor mostrará una disminución en la tasa de disparos con estimulación continua sobre la piel.

\section{Clasificación del tacto}

El tacto se clasifica en activo y pasivo. El tacto pasivo se determina cuando la actividad somatosensorial se produce por la estimulación de los receptores de la piel porque un objeto es colocado sobre la piel; mientras que en el tacto activo el sujeto activa interacciones con el medio explorando objetos y tocándolos. Gibson (1966, citado en Matlin y Foley, 1996), consideraba que el tacto activo es más preciso que el pasivo y señaló la importancia del tacto activo; así mismo, afirmó que debido a que los humanos también son dependientes del sistema visual, la gente generalmente confía en la información visual si se encuentra ante un conflicto de información visual y táctil, pues la vista y el tacto son dominantes en sus áreas de especialización; la visión funciona mejor que el tacto para la percepción de características estructurales de los estímulos, como la forma o el tamaño, y a su vez el tacto funciona mejor para la percepción de la dureza y aspereza.

Los umbrales se dan a nivel de umbral absoluto y de discriminación de dos puntos. En el primero, algo se reporta la mitad de las veces; y el segundo mide la capacidad para notar que dos puntos de la piel están siendo tocados en lugar de uno solo. Se evalúan seleccionando dos puntos de diámetros angostos y con frecuencia los dos puntos se presentan de manera simultánea, pero en ocasiones se presentan en secuencia. Los umbrales de discriminación de dos puntos también son diferentes en diversas partes corporales. Estos corresponden a la cantidad del espacio ocupado por la parte corporal en la corteza.

\section{DOLOR}

Es considerado una experiencia privada de molestia (que lastima) o percepción de daño tisular real o de amenaza de sufrirlo. Tiene dos componentes básicos: el sensorial, relacionado con los sentidos y lo perceptual, siendo principalmente de protección; y el emocional, que es individual, no se puede compartir con los demás y es subjetivo.

Entre los fenómenos que aparecen se encuentran el umbral y la adaptación, surgiendo uno nuevo llamado tolerancia, que hace referencia al máximo nivel de dolor que un sujeto acepta voluntariamente. Algunas particularidades de la adaptación son que, aunque se describe como la pérdida de sensibilidad frente a un estímulo doloroso prolongado, no hay adaptación a dolores intensos, solo en dolores leves (estímulos de frío y calor poco dolorosos y punzantes) y no se presenta con temperaturas mayores a $46{ }^{\circ} \mathrm{C}$ (Schiffman, 2004, pp. 420-423). 


\section{APARTADO FINAL}

La importancia de la percepción en el aprendizaje es innegable. La percepción se puede dividir en tres subprocesos desde el punto de vista fisiológico (Davidoff, 1994, citado en Bravo, 2004):

- Detección: intervienen los receptores, es decir, los sentidos tanto internos como externos.

- Transducción y transmisión: procesos en los que se convierte energía de una forma a otra (la energía en una señal electroquímica que el sistema nervioso transmite).

- Procesamiento de la información: "El cerebro y los receptores procesan información sensorial en organismos de relativa simplicidad" (Bravo, 2004, p. 152).

Para enfrentar exitosamente el aprendizaje de la lectura y la escritura, se requieren ciertas destrezas que involucran los procesos perceptivos, tanto en percepción visual como en percepción auditiva, básicamente discriminación auditiva; también, se requieren destrezas motrices en el uso de manos y dedos para lograr ejecutar labores de escritura, esto implica a la vez una regulación tónico-postural general que le permita al estudiante manejar la estructuración espacio-temporal para codificar y decodificar las letras (Bravo, 2004, p. 10).

Al finalizar esta unidad, usted como estudiante ha hecho un recorrido por diferentes perspectivas de estos procesos psicológicos, dependiendo del autor, las condiciones neuropsicológicas, los aspectos que conllevan, su clasificación y sus efectos. Se espera que el futuro psicólogo principalmente considere hacer una comprensión holística del proceso, que debe entenderse como tal si se pretende hacer una buena valoración y diagnóstico del mismo.
Se sugiere la lectura del capítulo 3 del libro de Fernández-Abascal, Martín y Domínguez (2010).

\section{DEMOSTRACIONES}

A continuación, encontrará una serie de demostraciones que pueden ser desarrolladas durante el transcurso del semestre de manera particular fuera del aula, reforzando así las que se realizarán en cada sesión de clase:

Demostración 1. Acomodación (Matlin y Foley, 1996, p. 116). Párese frente a una ventana y coloque un dedo 20 centímetros en frente de sus ojos. Enfóquelo forzando al cristalino a que se haga más grueso. Observe qué tan borroso se ven todos los objetos por la ventana. Con un cristalino engrosado, los rayos luminosos de los objetos distantes se enfocan en un punto frente a la retina. Luego enfoque un objeto distante, forzando a que su cristalino se haga más delgado. Ahora su dedo se verá borroso. Con un cristalino aplanado, los rayos luminosos provenientes de los objetos cercanos se enfocan en un punto que estaría por detrás de la retina.

Demostración 2. Enmascaramiento auditivo (Coren et al., 2001, p. 188). Entre a su automóvil, encienda la radio sin arrancar el motor, busque música con un buen rango de frecuencias; al escuchar, tome nota particular de los sonidos con frecuencias altas y bajas, luego baje el volumen hasta donde apenas pueda oír esas frecuencias. Ahora proceda a encender el motor, pise el acelerador con el carro en neutro para que el motor trabaje a más revoluciones por minuto. Esto crea una fuente de ruido intenso de enmascaramiento de banda ancha. Luego proceda a escuchar las frecuencias altas y bajas que eran claramente audibles en la música antes de encender el automóvil. Suba el volumen hasta que las frecuencias sean apenas audibles otra vez 
y tome nota de la diferencia de volumen antes y después de que se introdujera el ruido.

Demostración 3. Potenciación producida por la adaptación (tomado de Schiffman, 2004, p. 442). Tome un sorbo de café fuerte y manténgalo en contacto con la lengua entre treinta y cuarenta segundos, escúpalo y luego tome un trago de agua simple. Esta le sabrá ligeramente simple. Inténtelo ahora con una solución concentrada de azúcar; ahora tome un trago de agua simple, notará que le producirá un sabor ligeramente amargo o agrio.

Demostración 4. Umbrales del tacto para diversas partes corporales. Tome un pequeño pedazo de algodón o pañuelo desechable y toque ligeramente las siguientes partes del cuerpo: la parte más gruesa de la planta del pie, la pantorrilla, la espalda, la nariz y el dedo pulgar. Observe que las partes del cuerpo no tienen una sensibilidad uniforme al tacto.

\section{ACTIVIDAD DE EVALUACIÓN}

\section{COMPLETE}

1. Las principales características físicas de las ondas luminosas son

$$
\mathrm{y}
$$
; se corres-

ponden de manera particular con una propiedad psicológica, a saber:
2. Las cuatro clases de tarea de agudeza visual son $\mathrm{y}$

3. El es una propiedad sonora del tono que corresponde a la complejidad de la combinación de las ondas sonoras.

4. $\mathrm{La}$ es la disminución en la sensibilidad cuando un estímulo se presenta continuamente.

5. Las responden a cambios en la estimulación, pero cesan de responder cuando hay presión continua sobre la piel.

\section{SOLUCIÓN}

1. Las principales características físicas de las ondas luminosas son longitud, amplitud y pureza; se corresponden de manera particular con una propiedad psicológica, a saber: matiz, brillantez y saturación

2. Las cuatro clases de tarea de agudeza visual son identificación, detección, resolución y vernier.

3. El timbre es una propiedad sonora del tono que corresponde a la complejidad de la combinación de las ondas sonoras.

4. La adaptación es la disminución en la sensibilidad cuando un estímulo se presenta continuamente.

5. Las fibras de adaptación rápida responden a cambios en la estimulación, pero cesan de responder cuando hay presión continua sobre la piel. 


\section{REFERENCIAS}

Alcaraz, V. y Guma, E. (2001). Texto de neurociencias cognitivas. México D.F.: Manual Moderno.

Ardila, R. (1973). Psicología fisiológica. México D.F.: Trillas.

Bravo, L. (2004). Las destrezas perceptuales y los retos en el aprendizaje de la lectura y la escritura. Una guía para la exploración y comprensión de dificultades específicas. Revista Electrónica Actualidades Investigativas en Educación, 4(1). Recuperado el 14 de noviembre de 2019, de https://www.redalyc.org/ articulo.oa?id=447/44740105

Cambria, E., Livingstone, A. y Hussain, A. (2012). The Hourglass of Emotions. En A. Esposito, A. M. Esposito, A. Vinciarelli, R. Hoffmann y V. C. Müller (eds.), Cognitive Behavioural Systems (pp. 144-157). cost 2102 International Training School, Dresden, Alemania, febrero 21-26 de 2011

Clark, D., Boutros, N. y Méndez, M. (2012). El cerebro y la conducta: neuroanatomía para psicólogos. México D.F.: Manual Moderno.

Coren, S., Ward, L., y Enns, J. (2001). Sensación y percepción. México D.F.: McGraw-Hill.

Fernández-Abascal, E., Martín, M. D. y Domínguez, J. (2010). Procesos psicológicos. Madrid: Editorial Psicología Pirámide

Papez, J. W. (1929). Neurología comparativa; un manual y el texto para el estudio del sistema nervioso de los vertebrados. Nueva York: Thomas Y. Crowell.

Schiffman, H. R. (2004). Sensación y percepción: un enfoque integrador. México D.F.: Manual Moderno.

Téllez-Vargas, J., Taborda, L. C. y Burgos, C. (2000). Psicopatología clínica. El síntoma en las neurociencias. Bogotá: Javegraf. 


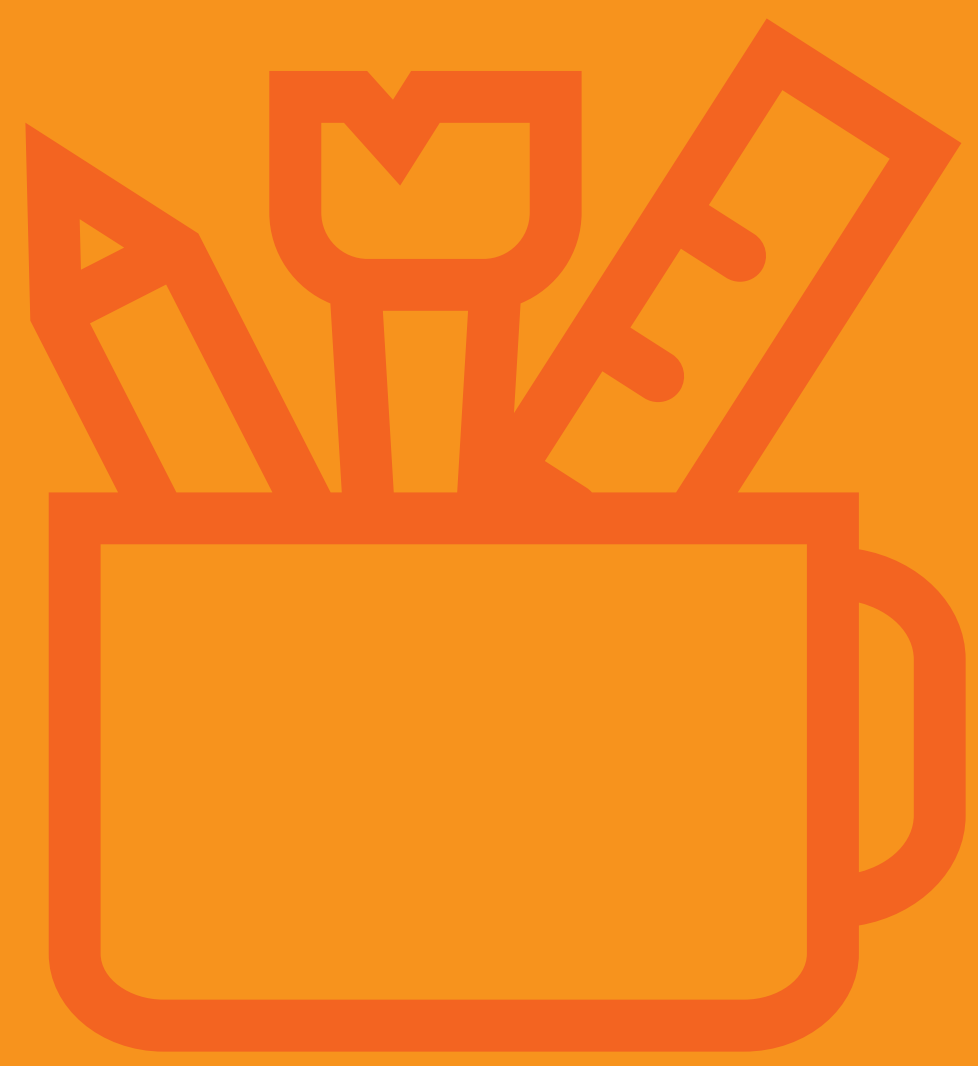

